\title{
Da história dos índios às histórias indígenas: descolonizando o ensino de história ${ }^{1}$
}

\author{
Nayara Silva de Carie* \\ Universidade Federal de Minas Gerais \\ Pablo Luiz de Oliveira Lima** \\ Universidade Federal de Minas Gerais
}

Resumo A partir de uma problematização das representações sobre os povos indígenas presentes em coleções didáticas utilizadas no ensino de História, este artigo tem o objetivo de analisar o lugar social de produção do conhecimento sobre a história dos índios. Questiona-se a hegemonia de narrativas sobre história indígena, de caráter colonialista e construída a partir de versões não-indígenas, presentes nos livros didáticos de História. Ao lado disso, são valorizadas pesquisas e produções bibliográficas mais atualizadas, que buscam compreender o processo colonial por meio de versões indígenas, não somente a partir do campo da História, mas, também, dos campos da Arqueologia, da Etnologia e da Literatura de autoria indígena. A metodologia de pesquisa consistiu no levantamento e na análise crítica de estudos acadêmicos recentes nos campos da História e da educação indígena, assim como das narrativas que abordam histórias indígenas presentes nas coleções didáticas do segundo segmento do Ensino Fundamental aprovadas pelo Programa Nacional de Livros Didáticos do ano de 2017 (PNLD/2017). Por meio da crítica a uma história colonialista dos povos indígenas, são apontados caminhos para a sua superação, utilizando pesquisas e narrativas construídas a partir das perspectivas dos próprios índios. Desse modo, pretende-se contribuir com a formação de professores nos cursos de Licenciatura em História, Pedagogia, Educação do Campo e Educação Indígena.

PALAVRAS-CHAVE: Educação indígena; Ensino de história; História indígena. 
From the history of the Indians to the indigenous histories: decolonizing the teaching of history

Abstract From a problematization of the representations about the indigenous peoples present in didactic collections used in the teaching of History, this article has the objective to analyze the social place of knowledge production on the history of the Indians. It questions the hegemony of narratives on indigenous history, of colonial character and constructed from non-indigenous versions, present in the didactic books of History. Alongside this, the most up-to-date bibliographical researches and productions are sought, which seek to understand the colonial process through indigenous versions, not only from the field of History, but also from the fields of Archeology, Ethnology and literature of indigenous authorship. The research methodology consisted in the survey and critical analysis of recent academic studies in the fields of History and indigenous education, as well as of the narratives that approach indigenous histories present in the didactic collections of the second segment of Elementary Education approved by the National Program of Didactic Books of the year 2017 (PNLD / 2017). Through criticism of a colonialist history of indigenous peoples, ways of overcoming them are pointed out, using researches and narratives constructed from the perspectives of the Indians themselves. In this way, it is intended to contribute to the training of History, Pedagogy, Field Education and Indigenous Education.

KEYWORDS: Indigenous education, History teaching, Indigenous history.

\section{Introdução}

A história dos povos indígenas no Brasil está mudando de figura. Até os anos 1970, os índios, supunha-se, não tinham nem futuro, nem passado. [...] Os historiadores, afeitos a fontes escritas - e escritas por seus atores - hesitavam ainda em pisar nas movediças areias da tradição oral ou de uma documentação sistematicamente produzida por terceiros: missionários, inquisidores, administradores, viajantes, colonos, intermediários culturais, em suma, com interesses próprios e geralmente antagônicos das populações descritas. [...]

Os índios, no entanto, têm futuro: e, portanto têm passado. Ou seja, o interesse pelo passado dos povos indígenas, hoje, não é dissociável da percepção de que eles serão parte do nosso futuro. A sua presença crescente na arena política nacional e internacional, sua também crescente utilização dos mecanismos jurídicos na defesa de seus direitos tornam a história indígena importante politicamente. Os direitos dos índios à sua terra, diz a Constituição, são históricos, e a história adquire uma imediata utilidade quando se trata de provar a ocupação. Mas ela tem também o caráter de resgate de dignidade que não se pode esquecer. (CUNHA, 2009, p. 125-126). 
Desde a promulgação da vigente Constituição brasileira, em 5/10/1988, os povos indígenas, no Brasil, têm o direito instituído de viverem de acordo com suas próprias culturas. Frente a séculos de colonização, há apenas trinta anos, o Estado brasileiro reconhece formalmente os direitos desses povos à sua própria "organização social, costumes, línguas, crenças e tradições.” (Constituição da República Federativa do Brasil, 1988, art. 231). O Capítulo VIII, "Dos Índios", no título VIII, "Da ordem social”, na atual Constituição, é resultado da ação de diversos indivíduos e coletivos indígenas, movimentos sociais, organizações não-governamentais e instituições ligadas ao próprio Estado brasileiro. Para Manuela Carneiro da Cunha, a Constituição de 1988 representa um avanço, por parte do Estado, em relação às "metas e ao jargão assimilacionista" e ao reconhecimento dos "direitos originários dos índios, seus direitos históricos". (CUNHA, 1992, p. 17).

A educação escolar indígena diferenciada é um desses direitos. A Lei de Diretrizes e Bases da Educação Nacional (LDBEN), de 1996, prevê que o "Sistema de Ensino da União", em colaboração com as agências federais, deve ofertar educação escolar bilíngue e intercultural aos povos indígenas, com o objetivo de "proporcionar aos índios, suas comunidades e povos, a recuperação de suas memórias históricas; a reafirmação de suas identidades étnicas; e a valorização de suas línguas e ciências". Essa legislação tem permitido o reconhecimento de metodologias indígenas de ensino-aprendizagem, a criação de cursos superiores de licenciatura indígena, bem como uma expressiva e crescente realização de novas práticas escolares marcadas por alianças com universidades públicas. Todo esse processo consolidou a noção do direito à memória diferenciada por parte dos povos indígenas, bem como o entendimento de que a preservação e a disponibilização de bens culturais que evidenciam as mais diversas histórias indígenas também são ações afirmativas. Tal contexto também criou condições para que, em poucos anos, houvesse um aumento significativo da produção de livros, filmes e outras obras publicadas de autoria indígena, com registros de suas versões da história. Tudo isso tem provocado um deslocamento nos estudos sobre a memória da realidade indígena na academia, partindo de uma história escrita sobre os povos indígenas para histórias propriamente indígenas, em termos de autorias, perspectivas, metodologias e objetivos.

No campo mais específico da historiografia, é possível considerar que, desde o século XVI, muitas obras foram escritas sobre os povos indígenas do continente americano pelas mãos de homens brancos ocidentais ligados à organizações colonizadoras, como as igrejas cristãs, companhias comerciais e os próprios Estados europeus e americanos. Assim, pode-se afirmar que existem, literalmente, séculos de história escrita sobre os índios de autoria não-indígena. Todavia, com o surgimento e o desenvolvimento da Antropologia, da Etnologia indígena, da Arqueologia, bem como a aproximação dessas ciências com a História desde o século XIX, diversos historiadores, antropólogos e cientistas sociais não-indígenas se esforçaram por repensar a história dos índios, propondo-a numa perspectiva dos próprios povos indígenas. A antropóloga Manuela Carneiro da Cunha, por exemplo, tem contribuído para fortalecer esse deslocamento epistemológico também no campo da História e do seu ensino, transitando da história dos índios para uma história indígena. 
Em 1992, Cunha organizou o livro História dos Índios no Brasil, uma coletânea de trabalhos em diferentes áreas das Ciências Humanas resultantes de diferentes pesquisas que abordaram, de alguma maneira, o passado de alguns povos indígenas, divididos por regiões do território brasileiro. A produção da obra teve início em 1988, mesmo ano da Constituição, e seus capítulos apresentam o estado da arte de pesquisas acadêmicas sobre história indígena no início da década de 1990: um conjunto de "estudos de casos" ou "fragmentos de conhecimento" que, nas palavras de Cunha, não teriam a pretensão de preencher lacunas, mas, ao contrário, de possibilitar "imaginar" essas lacunas. À época, ela avaliava que ainda sabia-se "pouco da história indígena: nem a origem nem as cifras da população são seguras, muito menos fatos ocorridos. Mas, progrediu-se (...)". Cunha avaliava que "pelo menos" era possível perceber "a extensão do que não se sabe" (1992, p.11) Para a autora, a História dos Índios no Brasil tinha também o objetivo de alertar para algumas "armadilhas" no campo da história indígena.

Entre as armadilhas elencadas por Cunha (1992) está a "a ilusão do primitivismo", do bom-selvagem, que se desdobra na ideia de que as sociedades indígenas vivem paradas no tempo, não cabendo, portanto, "procurar-lhes a história". Francisco Varnhagen (1953, p. 31 tomo I), um dos primeiros historiadores brasileiros, ao parafrasear o que Georg Hegel escrevera sobre o continente africano, afirmou sobre os índios que "de tais povos na infância não há história: há só etnografia”. Uma armadilha do colonialismo que se perpetua porque, segundo Cunha (1992, p.11), "nos agrada a ilusão de sociedades virgens".

Passados vinte e cinco anos da publicação dessa obra, é necessário avaliar a situação da história indígena e de seu ensino na educação básica e superior, considerando as pesquisas acadêmicas sobre a temática indígena. Assim, este artigo tem o objetivo de analisar o lugar social de produção do conhecimento sobre a história dos índios, buscando compreender a presença indígena em materiais didáticos e apontar caminhos para a tentativa de superar algumas dificuldades identificadas no ensino de história indígena.

A partir da experiência dos autores como docentes dos cursos de Licenciatura em História, Pedagogia, Licenciatura do Campo e Licenciatura Indígena, parte-se da hipótese de que o ensino de História do Brasil, em especial sobre o período inicial da colonização (séculos XV a XIX), abordado por livros didáticos e na educação básica não-indígena brasileira, continua representando os povos indígenas em uma perspectiva colonialista, insensível à perspectiva de suas próprias versões sobre a história.

Tal hipótese engendra questões que problematizam o lugar da educação para as relações étnico-raciais, mais especificamente da história indígena, no ensino de história escolar, dentre as quais se destaca: como seria possível descolonizar o ensino de uma disciplina tão carregada de tradição eurocêntrica, nacionalista e preconceituosa em relação aos povos indígenas, como a História? Como desconstruir estereótipos criados pela história "tradicional" sobre os índios? Como a história indígena pode contribuir para o ensino de História na educação básica brasileira não-indígena, bem como na educação escolar indígena diferenciada e intercultural? 
Para responder a essas questões, este artigo propõe uma análise sobre o ensino de histórias indígenas nos livros didáticos brasileiros, aprovados pelo Ministério da Educação por meio do Programa Nacional do Livro Didático, do ano de 2017. Em seguida, busca-se problematizar o caráter colonialista do ensino de História por meio da ampliação de pesquisas em história indígena, incluindo a releitura de fontes primárias e bibliográficas sobre a história do processo inicial de colonização das Américas, bem como a valorização de obras literárias de autoria indígena. Como resultado, vislumbramos possibilidades de práticas descolonizadas para o ensino de história indígena.

\section{Da história colonizada à educação indígena diferenciada}

O processo colonial alterou profundamente as condições em que viviam e vivem as populações ameríndias. Os conflitos, o comércio, a escravização, as epidemias, a catequese transformaram rápida e intensamente os sistemas sociais nativos, introduzindo novos objetos e novas relações. (FAUSTO, 2002, p. 17).

O território brasileiro é atualmente habitado por cerca de 900 mil sujeitos indígenas, compondo 253 povos que falam mais de 150 línguas pertencentes a 20 famílias linguísticas diferentes ${ }^{3}$. Há mais de cinco séculos, esses povos têm enfrentado o processo de colonização, caracterizado pela usurpação de suas terras, escravização de seus ancestrais e imposição de valores ocidentais e capitalistas sobre suas culturas. É sempre necessário lembrar a enorme diversidade dos povos indígenas antes da colonização e, ainda hoje, o que significa, necessariamente, um universo plural no que diz respeito a narrativas históricas.

No entanto, desde os primeiros contatos entre europeus e indígenas, no final do século XV, até a década de 1980, o conhecimento histórico sobre esses povos foi produzido hegemonicamente a partir de uma perspectiva eurocêntrica. Trata-se de uma história escrita por colonizadores e seus descendentes. Isso significa que desde o período inicial da colonização do Brasil até fins do século XX, as obras escritas sobre o próprio processo colonial - crônicas, cartas e relatos primários, até obras de historiografia representaram as culturas indígenas a partir de um olhar não-indígena que, na sua grande maioria, os considerava como inferiores em relação à cultura europeia, cristã, escravista e colonizadora. Da colônia até a última ditadura militar, o lugar dos indígenas na história oficial foi o de matriz do povo brasileiro, porém fadado ao desaparecimento ou assimilação pela sociedade brasileira.

A partir do final do século $\mathrm{XX}$, as lutas e os esforços dos próprios povos indígenas organizados em um "movimento indígena de âmbito nacional" (CUNHA, 1992, p. 17), bem como pesquisas acadêmicas nos campos da Antropologia, Arqueologia, História e Educação, começaram a transformar o conhecimento histórico acerca dos povos indígenas. Pesquisas buscaram compreender a multiplicidade das histórias indígenas para superar o viés colonialista. Segundo Fausto (2002, p. 17), a história indígena é fruto da aproximação entre História e Etnologia, no sentido de se tentar "compreender e transmitir algo da vivência e da perspectiva do grupo estudado". Ao mesmo tempo, tem havido, nesse período, um expressivo crescimento do número de 
livros de autoria indígena publicados no Brasil, muitos de autoria coletiva, bilíngues ou em línguas indígenas, com narrativas e interpretações da história indígena centradas nas lógicas das próprias culturas indígenas ${ }^{4}$.

Esse movimento epistemológico relaciona-se às políticas públicas formuladas para a educação. No ano de 2002, o Brasil tornou-se signatário da Convenção 169 da Organização Internacional do Trabalho (OIT) ${ }^{5}$, tendo esta entrado em vigor em julho de 2003. O artigo sétimo dessa Convenção reforça a necessidade de que, por meio de ações concretas, os governos devem desenvolver estratégias e ações que promovam a melhoria das condições de trabalho, nível de saúde e educação da população indígena com a sua própria participação e colaboração. Essa legislação internacional legitima e estimula o trabalho no campo da história e da educação indígena.

Mais recentemente, o Estado brasileiro aprovou a Lei Federal 11.645/2008, tornando "obrigatório o estudo de história e cultura afro-brasileira e indígena" em todas as redes de educação básica, pública e privada.

No ano de 2012, foi aprovada a Lei 12.711, conhecida como "Lei de Cotas", que obriga as instituições federais de ensino superior a reservarem vagas para os estudantes indígenas oriundos de todas as redes públicas.

Não se pode deixar de mencionar que todo esse movimento de inclusão dos indígenas no âmbito das normas nacionais e internacionais é impulsionado pela organização de grupos indígenas em torno da luta pelos seus direitos. Esse movimento de luta pela implementação e ampliação dos direitos dos índios impulsiona o surgimento de obras de autoria indígena sobre a História de seus povos.

No entanto, ao se analisar as coleções didáticas aprovadas pelo Programa Nacional do Livro Didático (PNDL), referente ao ano de 2017, foi possível perceber que as histórias indígenas presentes nas coleções não têm acompanhado o ritmo da legislação, nem das pesquisas em História indígena ou da produção bibliográfica de autoria indígena.

Apesar dos esforços empreendidos por parte de pesquisadores, professores e do próprio Estado, uma década após a aprovação e entrada em vigor da Lei 11.645/2008, a história ensinada em livros didáticos de educação básica ainda aborda os povos indígenas em uma perspectiva eurocêntrica, ou seja, atrelados ao protagonismo histórico dos colonizadores europeus e de maneira generalizada, caindo nas armadilhas apontadas em 1992 por Manuela Carneiro da Cunha. Essa visão generalizada é percebida em representações dos indígenas como um grupo étnico homogêneo, bem como a quase ausência de versões elaboradas pelos próprios povos indígenas sobre suas histórias. Isso ocorre não apenas em livros didáticos, como analisaremos adiante, mas no próprio texto da Lei 11.645/2008, que trata os negros e indígenas como "dois grupos étnicos”, desconsiderando a enorme diversidade de povos indígenas, africanos e afro-brasileiros. ${ }^{6}$

O quadro é também preocupante quando se constata que em cursos de Licenciatura em História, não existem disciplinas obrigatórias no campo da história 
indígena, nem mesmo disciplinas sobre a temática na perspectiva da história dos índios. Assim, pode-se afirmar que há um descompasso entre o que tem sido produzido sobre a história indígena e o ensino de História. Isso se constitui um problema com diversas implicações para a formação de professores, para a educação das relações étnico-raciais, para a superação do racismo e do preconceito contra os povos indígenas e para o cumprimento da Constituição, da Convenção 169 da OIT, da LDBEN e da Lei 11.645/2008.

Para compreender melhor tal descompasso, será realizada uma discussão sobre como os povos indígenas são representados nos livros didáticos de História do segundo segmento do Ensino Fundamental aprovados pelo PNLD/2017. A escolha por analisar as narrativas didáticas sobre as histórias indígenas deve-se ao fato de que as narrativas didáticas contribuem para formar o modo como compreendemos o mundo a nossa volta e, também, porque nos informam sobre concepções sobre a História indígena e sobre os sujeitos índios que são legítimas em nossa sociedade. Ancorado nos currículos oficiais que regem o ensino no Brasil, o PNLD elabora os critérios de avaliação das coleções didáticas. Um dos critérios de avaliação do PNLD é a presença da história e cultura indígenas. No entanto, segundo a própria avaliação do PNLD/2017, no Guia de Livros Didáticos, tanto no primeiro quanto no segundo segmento do ensino Fundamental, a questão indígena permanece entre os temas que apresentam alguns avanços, mas que ainda necessita de abordagens que considerem os estudos historiográficos mais recentes. (BRASIL, 2016, p. 21,24, 25 e 36).

De acordo com a representação dos indígenas nas narrativas didáticas presentes nas coleções que foram avaliadas pelo PNLD 2017, questiona-se como essas representações ajudam a compreender o Brasil atual? Quais os papéis desempenhados por essas populações na sociedade brasileira? O que essas representações nos dizem sobre os modos como as culturas indígenas estão presentes em nossa sociedade? Como o estudo dos sujeitos indígenas proposto nas narrativas presentes nas coleções didáticas ajuda a compreender a realidade brasileira?

\section{Os indígenas nas coleções didáticas de História do segundo segmento do Ensino Fundamental}

Jörn Rüsen ${ }^{7}$ (2011) considera que, para compreender o presente e orientar as suas ações no tempo, os sujeitos buscam referências no passado. Para o autor, as narrativas sobre o passado que circulam nas sociedades, inclusive aquelas que são ensinadas na escola, interferem no modo como os sujeitos narram, compreendem, atuam no presente e constroem seus projetos de futuro. Desse modo, a maneira como as narrativas didáticas representam os sujeitos indígenas, as relações entre grupos indígenas de uma mesma comunidade, entre os diferentes povos indígenas, bem como as relações entre os índios e os não-índios, compõe modelos narrativos que os estudantes utilizam para compreenderem as dinâmicas sociais que envolvem esses sujeitos na sociedade brasileira atual. É importante ressaltar que as narrativas didáticas sobre os índios, assim como as várias narrativas que circulam na sociedade, também se constituem em referenciais para a construção de modelos narrativos que os estudantes utilizam para compreender as relações que se desenvolvem entre diferentes grupos sociais e não 
apenas aquelas envolvendo os indígenas. De acordo com Rüsen (2011, p. 122), isso ocorre porque o modo como os diversos sujeitos ou grupos sociais são representados nas narrativas históricas contribui para a construção das identidades dos estudantes como sujeitos históricos?

Nesse sentido, uma característica apontada por Rüsen (2011), como sendo importante ao se pensar na construção de uma narrativa de História é a presença da pluriperspectividade, ou seja, a apresentação da experiência histórica a partir de diferentes perspectivas, uma vez que o mesmo fato pode ser percebido pelos sujeitos afetados de diferentes formas, inclusive, contrárias. Além disso, os fatos também podem ser percebidos de formas diferentes pelos observadores, e ainda, pelos historiadores, o que aponta para diferentes dimensões de pluriperspectividade.

A pluriperspectividade nas narrativas de cunho histórico contribui para pensar a transitoriedade e a dinamicidade do passado. Permite, ainda, perceber o passado a partir da sua complexidade, considerando a heterogeneidade, as tensões e correlações de forças, as ações, e as intenções dos sujeitos e dos grupos sociais. No entanto, as narrativas construídas a partir de um único ponto de vista não tornam visível a diversidade social, as relações entre os diversos sujeitos e grupos sociais que partilham um mesmo espaço e contextos históricos. Contribuem ainda para a construção da ideia de passado como algo estático ou engessado, pronto e acabado.

A escolha da forma de narrar o passado se relaciona com as narrativas que circulam na sociedade e que estão relacionadas à identidade, à memória, ao modo como os sujeitos veem a si e aos outros. Ainda que as narrativas didáticas sejam apropriadas de modos diferentes por estudantes e professores, para se pensar em um ensino de História que contemple histórias e culturas indígenas e que se oriente pelo respeito à diversidade, faz-se necessário pensar em construções narrativas que explicitem as diversas vozes do passado pois, à medida que as formas de narrar o passado fazem parte da cultura histórica de uma sociedade, elas também alimentam e dão suporte às narrativas que são construídas no presente. Logo, torna-se importante identificar elementos nas composições narrativas que invisibilizam e ou homogeneízam os sujeitos, promovendo a naturalização e, por conseguinte, a manutenção de relações de exclusão social, econômica, étnica, racial e religiosa.

Para compreender como as narrativas didáticas têm representado os indígenas, primeiramente, foi realizado um mapeamento de quatorze coleções didáticas de História do segundo segmento do Ensino Fundamental, aprovadas pelo PNLD 2017. Para tal, iniciou-se o trabalho para a localização e aquisição das coleções didáticas aprovadas pelo PNLD de 2017 em bibliotecas públicas, escolares e editoras. Essas obras foram lidas com o objetivo de identificar narrativas referentes aos indígenas. Identificados os capítulos que abordavam a história indígena, os textos dos livros didáticos foram escaneados e catalogados por temas e períodos históricos.

Em seguida, foram realizadas as leituras das narrativas escaneadas e, a partir destas, foi feita uma classificação em relação ao modo como os sujeitos indígenas eram representados (em coletivos homogêneos ou heterogêneos; como sujeitos individuais 
ou coletivos); às temporalidades por meio das quais eram representados (no tempo presente, no passado ou na relação entre ambos os tempos); bem como à presença da perspectiva indígena nas narrativas históricas encontradas nos livros didáticos.

Dentre as coleções analisadas referentes aos anos finais do ensino fundamental, identificamos que os povos indígenas estão mais presentes nos livros do sexto ano, uma vez que, nos livros referentes a este período da escolaridade, os indígenas estão representados em 11 das 14 coleções. Os temas tratados nesses livros referem-se a elementos da cultura indígena no presente, tais como a diversidade de povos indígenas, os objetos da cultura material, os mitos indígenas, bem como a contação de histórias e a sua função nas sociedades indígenas.

Nos livros referentes ao sétimo ano, os grupos indígenas são representados de modo superficial no período pré-cabralino. Já no período colonial, são inseridos no contexto das Missões jesuíticas, da exploração da mão de obra indígena, bem como no contexto da escravidão e da resistência. As narrativas também abordam os primeiros contatos entre indígenas e portugueses, com ênfase na atuação portuguesa. Ressalta-se uma exceção à Confederação dos Tamoios, processo em que a ação indígena se mostrou mais expressiva.

Nos exemplares referentes ao oitavo ano, os grupos indígenas são apresentados no contexto das Bandeiras, atuando ora como aliados, ora como opositores no processo de interiorização do território, como inspiração para o movimento literário denominado Romantismo.

Nos volumes referentes ao nono ano, pode-se perceber que os povos indígenas são representados, em sua maioria, no contexto da legislação e das instituições, contudo, com pouca ou quase nenhuma ênfase nas ações dos próprios indígenas na conquista desses direitos, bem como nas implicações da instituição desses direitos. Foi possível identificar também os indígenas sendo representados no governo Vargas, no que refere aos direitos indígenas na Constituição de 1934, na conquista dos direitos indígenas na Constituição de 1988, no contexto do Projeto Rondon, na obrigatoriedade da inclusão da temática indígena nos currículos brasileiros atuais e, atualmente, na luta pela terra.

Diante desses elementos identificados nas narrativas didáticas sobre a história indígena e estabelecendo um diálogo com a discussão realizada por Manuela Carneiro da Cunha, é possível se pensar em armadilhas da história indígena presentes nas narrativas didáticas: a armadilha da homogeneidade, a armadilha da visão da história indígena vista de fora e a armadilha do indígena como um outro, que não pertence ao "nós".

1 - A armadilha da homogeneidade dos povos indígenas como estratégia de simplificação e invisibilidade de questões políticas, étnicas e sociais que envolvem esses povos. A partir da análise das narrativas didáticas investigadas, pudemos perceber que os indígenas aparecem na história do Brasil em diversos períodos, sendo, contudo, os temas, em sua maioria, desenvolvidos de maneira superficial. Os sujeitos indígenas, majoritariamente, são repre- 
sentados de forma coletiva e homogênea, embora haja uma enorme diversidade e pluralidade entre eles. Desse modo, escapa às narrativas didáticas a dinâmica processual das múltiplas experiências dos indígenas, suas diferenças, bem como suas relações com os não-indígenas. As obras carecem de representações sobre as culturas indígenas que trazem à tona a sua dinamicidade e apresentem os sujeitos indígenas desempenhando papéis ativos no processo de construção de identidades culturais no passado e no presente.

2-A armadilha da história indígena vista de fora: as obras analisadas quase nunca apresentam a visão indígena dos acontecimentos. Assim, a história sobre os indígenas é, na grande maioria das vezes, narrada a partir do estudo das percepções dos acontecimentos de povos não-indígenas. As percepções dos povos indígenas de sua própria história são muito pouco ou não são apresentadas.

3 - A armadilha do indígena como o "outro", aquele que não faz parte do "nós". Nada é dito, por exemplo, sobre os indígenas que saíram das suas comunidades tradicionais ao longo do tempo, que foram viver nas cidades, constituíram famílias com não-índios. Os índios são representados como um grupo à parte. Nas narrativas referentes às histórias indígenas presentes nos livros didáticos analisados percebe-se uma visão essencialista e colonialista sobre os povos indígenas, na qual os índios são representados somente pelos não-indígenas como um grupo homogêneo, e como o "outro", ou seja, aquele que não faz parte do "nós".

Diante disso, compreende-se que, para se tentar evitar as armadilhas que foram identificadas nos livros didáticos analisados, é necessário trazer para o ensino da história indígena, narrativas construídas a partir das perspectivas dos próprios povos indígenas.

\section{A literatura e história de autoria indígena e o ensino de História}

Uma fonte pouco utilizada para o trabalho com a história indígena é a literatura de autoria dos próprios indígenas. Essas obras constituem o universo das publicações de autoria indígena no Brasil, que está em expansão desde meados dos anos 1990. A Universidade Federal de Minas Gerais conta com uma coleção especial intitulada Acervo Indígena (ACIND-UFMG). As obras do ACIND-UFMG, em especial os livros de autoria indígena, podem aproximar o ensino de História das pesquisas sobre história indígena, dos debates teóricos e práticas pedagógicas relacionadas à Lei 11.645/2008, a qual tornou obrigatório o ensino de história indígena na educação básica brasileira. Ademais, neste momento, pesquisadores, como Boaventura de Souza Santos (2010), têm fortalecido a necessidade da descolonização e a construção de novas epistemologias, fazendo-se necessário refletir em como a história indígena tem sido trabalhada no ensino de História e como este trabalho, poderia incorporar novas abordagens.

Atualmente, existem mais de 530 títulos de livros de autoria indígenas publicados no Brasil de acordo com a pesquisadora Amanda Lima (2012, p.147). Em suas palavras: 


\begin{abstract}
Os livros indígenas e suas múltiplas grafias nos permitem conhecer a história e a arte narrativa desses povos, bem como suas cerimônias, crenças e festas, mas, mais que isso, permitem-nos aproximar da visão de mundo e da realidade de cada povo autor. A história - na maioria das vezes narrada pelos velhos, que contam desde quando só seus antepassados existiam e nem o céu estava completamente formado ainda até os dias de hoje - dos massacres, da luta pela terra e pelos direitos de ser índio é apresentadas de forma firme e coesa em vários livros, nos quais os índios se apresentam como povos fortes e lutadores, que conseguem, apesar de todas as estatísticas contrárias, sobreviver e manter viva a sua tradição e cultura.
\end{abstract}

O ensino de história, ao abordar a história indígena, vê-se diante de um cenário plural e polifônico, que possibilita um trânsito interdisciplinar entre as várias frequências de análise, desde a cultura material, passando pelas narrativas escritas dos cronistas, antropólogos, historiadores, até os relatos orais e literários contemporâneos de autoria indígena. A perspectiva da história indígena busca analisar os processos históricos a partir do ponto de vista daqueles povos, seja em obras de autoria indígena ou de autores não-indígenas que buscam uma perspectiva crítica sobre a colonização, rompendo com representaçõess preconceituosos que cristalizam uma identidade e um lugar social fixo para o indígena nas análises de ciências humanas e sociais ocidentais. ${ }^{8}$

Entre as centenas de obras publicadas de autoria indígena, podemos destacar algumas que carregam referências mais explícitas à história indígena. Uma delas é o livro Huni Kuin Hiwepaunibuki / A história dos caxinauás por eles mesmos / La historia de loscashinahuas por ellosmismos, publicado em 2013 e organizado por Eliane Camargo e Diego Villar a partir de narrativas compartilhadas coletivamente pelo povo HuniKuin, que habita o território do estado do Acre, na fronteira com o Peru. Nas palavras dos autores TexerinoKirinoCapitán e Alberto Roque Toribo, "Os caxinauás surgiram, cresceram e seguem, desde então, aumentando." O livro mostra "um pouco de sua história, seus rituais, seus encontros com os iaminauás [...]. É por isso que apresentamos esses textos sobre a História de nosso povo, para contar aos nossos filhos de agora e aos futuros como eram nossos Antepassados".

Os autores consideram necessário registrar e difundir as histórias Huni kuin, por meio do livro, para contribuir com o trabalho de educação indígena, formando as novas gerações sobre as diferentes formas de trabalhar a memória: "Antigamente, nossos antepassados escutavam e viam seus costumes, agora nós não. Não vemos mais como era antigamente: não fazemos mais o txirim, 'dança para trás', a captação de memória com pimenta, o passar do muka, dieta de cobra [...]”. Interessante a menção ao Ha metsa katsi yutxiwen hama mekeidan, que é um ritual para "captar" a memória das coisas que passam pela língua, como a fala e os cantos, de modo rápido. Consiste em aplicar pimenta ardida na língua, para ativar a memória. E a muka é uma planta com a qual uma pessoa deve se banhar para ser inteligente, boa trabalhadora e boa caçadora, conforme Camargo; Villar (2013, p. 31). Existem, é verdade, inúmeros livros sobre os Huni kuin, ou caxinauás. A língua hantxakuin, falada por este povo, está entre as mais publicadas das línguas amazônicas. O livro Huni Kuin Hiwepaunibuki, por se tratar de narrativas apresentadas pelos próprios Huni-kuin, traduzidas para português e espanhol, é apenas um exemplo. 
As histórias apresentadas pelo livro têm embasamento na memória oral dos narradores. São memórias coletivas que tratam de acontecimentos do passado dos hunikuin de uma maneira diferenciada. Não existe uma preocupação com uma cronologia precisa ou datas de calendário. Os acontecimentos são narrados sem tempos passados marcados por outras divisões, conforme a citada obra dos autores Camargo e Vilar (2013, p. 143, 155, 175 e 177): "Naquela época", "Uma vez", "Quando morávamos em terra firme", “Quando viviam no barranco". Às vezes, o marcador temporal parece referir-se a um tempo cíclico, que se repete anualmente: "Por essa época entre junho, julho." (CAMARGO; VILLAR, 2013, p. 165). Muitas das histórias referem-se a acontecimentos mais precisos que ocorreram no passado recente, como o contato com os não-índios ("O primeiro encontro com um nauá") e com antropólogos estrangeiros.

Outro exemplo é a obra Histórias, mitos e lendas do povo Baré, também de autoria coletiva da Comunidade Indígena Tabocal dos Pereiras. O livro foi feito a partir de "pesquisas e pequenas entrevistas com os mais velhos". Os marcadores são característicos do que na sociedade ocidental consideramos como mitos "naquele tempo", "Naquela época”, “Um dia”, "No princípio", "Antigamente”(BARÉ, p. 13,17 e 18). Apesar de incertos, são marcadores temporais do tempo passado que, pela primeira vez, passam da memória viva para a escrita impressa. No caso dos Baré e dos Huni-kuin, as histórias em suas perspectivas são suas próprias memórias.

O que marca essas e várias outras obras de história indígena é o rompimento das fronteiras entre história e mito, com narrativas que se baseiam na memória e explicam o passado sem, no entanto, um compromisso com a verdade definitiva. Destaca-se, acima de tudo, o testemunho, a memória a partir da própria vivência, que inclui as histórias aprendidas, apropriadas, transformadas e reapresentadas.

É necessário enfrentar o lugar problemático e, ao mesmo tempo, potencial da história indígena no ensino de História. Isso passa pela ampliação crítica e aprofundada de fontes, problemas e possibilidades apresentadas pelas pesquisas em História e educação indígena. Para tanto, o professor de História é convidado a analisar de forma crítica os materiais do ensino de História disponíveis para o ensino básico brasileiro, bem como a produção de literatura de autoria indígena.

De acordo com Cunha (2009, p. 126), o campo da história indígena no Brasil, diferentemente do México e do Peru, contou com muito menos interesse por pesquisadores de História e Arqueologia, brasileiros e estrangeiros. Para ela, em tom otimista, no Brasil a história indígena, "[...] ficou virgem, ou quase. E está noiva não de uma ideologia de Estado, mas do movimento indígena”. Esta afirmação permite pensar em possibilidades de práticas educacionais diferenciadas, mas também carrega uma questão angustiante: na ausência de uma política de Estado, como aproximar o movimento indígena das escolas não-indígenas, restituindo o devido lugar dos povos indígenas no ensino de História? 


\section{Considerações finais}

Por meio de uma problematização das representações sobre os povos indígenas presentes em coleções didáticas aprovadas pelo PNLD/2017, foi possível identificar representações da história indígena que se relacionam à visões homogêneas destes grupos, a uma história dos índios vista de fora, em que as vozes dos mesmos não estão presentes, e, ainda, uma visão dos indígenas como "o outro", distanciado do "nós".

Dessa constatação, emerge a necessidade de se criar alternativas para essas armadilhas da História indígena. Desse modo, conclui-se este artigo propondo que um caminho possível para responder a esta questão é o trabalho com livros de autoria indígena na sala de aula. Esta prática tem o sentido tanto de formar os estudantes do ensino básico, quanto os próprios professores, fazendo frente à ausência de uma formação inicial em História indígena por meio de uma formação continuada e em serviço, sobre esta temática. A aproximação com as próprias versões indígenas da História pode ser uma boa oportunidade para se evitar as armadilhas da história dos índios, que vem sendo narradas.

No entanto, o problema do acesso a materiais como livros de autoria indígena, é uma realidade para docentes da educação básica e mesmo superior. Poucos autores indígenas conseguem trânsito no mercado editorial dominante e, a maioria das obras de autoria indígena tem uma circulação restrita nas bibliotecas de universidades e escolas básicas. Algumas iniciativas de reunião e publicização de livros de autoria indígena, portanto, merecem ser consideradas e indicadas. Uma dessas iniciativas é o Acervo Indígena da Universidade Federal de Minas Gerais (Acind-UFMG), uma coleção especial vinculada ao sistema de bibliotecas dessa universidade. O Acind-UFMG foi criado em 2012 e abriga uma coleção de livros de autoria indígena, e outrosmaterias de referência sobre a temática indígena, em sua grande maioria publicados no século XXI. Esse acervo está disponível para consulta presencial no Setor de Obras Raras e Coleções Especiais da Biblioteca Central da UFMG, em Belo Horizonte, MG.

Acima de tudo, é necessário que o professor de História tenha uma percepção crítica acerca de narrativas que se pretendem únicas e definitivas. Talvez o mais importante passo no caminho de uma história dos ou sobre os índios para a história na perspectiva e autoria propriamente indígenas, seja o uso da expressão sempre no plural: "histórias indígenas". Assim, o ensino de histórias indígenas possibilita pensar em estratégias metodológicas para fazer emergir, em um cenário público, as histórias contadas pelos indígenas e fomentar o diálogo entre estas e as histórias já consolidadas pela academia e pela história escolar.

\section{Referências}

ALMEIDA, Maria Inês de. Desocidentada: experiência literária em terra indígena. Belo Horizonte: Editora UFMG, 2009.

ALMEIDA, Maria Regina Celestino de. Metamorfoses indígenas: identidade e cultura nas aldeias coloniais do Rio de Janeiro. Rio de Janeiro: Arquivo Nacional, 2003.

ANASTASIA, Carla Maria Junho; RIBEIRO, Vanise Maria.Piatã: História. Curitiba: Positivo, 2015. 
APOLINÁRIO, Maria Raquel. Projeto Araribá: História. São Paulo: Moderna, 2014.

AZEVEDO, Gislaine; SERIACOPI, Reinaldo. Projeto Teláris: História. São Paulo: Ática, 2015.

BARÉ, Índios. Histórias, mitos e lendas do povo Baré/comunidade Indígena Tabocal dos Pereira. Belo Horizonte: FALE/UFMG, 2007.

BARRETTO, E. S. S. (org.) Os Currículos do ensino fundamental para as escolas brasileiras. São Paulo: Fundação Carlos Chagas; Campinas: Autores Associados, 1998.

BERUTTI, Flávio. História para nosso tempo. Curitiba: Positivo, 2015.

BOULOS JÚNIOR, Alfredo. História, sociedade e cidadania. São Paulo: FTD, 2015.

BRAICK, Patrícia Ramos. Estudar História: das origens do homem à era digital. São Paulo: Moderna,2015.

BRASIL. Congresso Nacional. Constituição da República Federativa do Brasil. Brasília, DF, 1988. Disponível em <http://www.planalto.gov.br/ccivil_03/Constituicao/ConstituicaoCompilado.htm>. Acesso em: 10 out. 2017.

BRASIL. Ministério da Educação. Lei de Diretrizes e Bases. Lei no 9.394/96, de 20 de dezembro de 1996.

BRASIL. Congresso Nacional. Lei 11.645/2008. Brasília, DF, 2008. Disponível em:<http:// www.planalto.gov.br/ccivil_03/_ato2007-2010/2008/lei/111645.htm>Acesso em: 10 out. 2017.

BRASIL. Congresso Nacional. Lei 12.711. Brasília, DF, 2012. Disponível em: <http://portal. mec.gov.br/cotas/perguntas-frequentes.html . Acesso em: 10 out. 2017.

BRASIL. Ministério da Educação. Parecer do MEC/CNE/CP n ${ }^{\circ}$ 11/2009. Brasília, DF, 2009. Disponível em:<http://portal.mec.gov.br/dmdocuments/parecer_minuta_cne.pdf $>$. Acesso em: 4 nov. 2012.

BRASIL. Congresso Nacional. Plano Nacional de Educação. Lei 13.005/2014. Brasília, DF, 2014. Disponível em <http://www.planalto.gov.br/CCIVIL_03/_Ato2011-2014/2014/Lei/ L13005.htm>. Acesso em 11 nov. 2017.

BRASIL. Palácio do Planalto. Decreto 5.051/2004, promulga a Convenção no 169 da Organização Internacional do Trabalho - OIT sobre Povos Indígenas e Tribais. Brasília, DF, 2004. Disponível em <http://www.planalto.gov.br/ccivil_03/_ato2004-2006/2004/decreto/d5051. htm>. Acesso em 20 ago. 2017.

BRASIL. Ministério da Educação. Orientações e Ações para a Educação das Relações étnico-Raciais. Brasília, DF, 2006. Disponível em:<http://portal.mec.gov.br/dmdocuments/orientacoes_etnicoraciais.pdf>. Acesso em: 4 ago. 2017.

BRASIL. Ministério da Educação, Secretaria de Educação Básica. Orientações curriculares nacionais para o ensino médio. Volume 1: Linguagens Códigos e suas Tecnologias. Brasília, DF, 2006. Disponível em:<http://portal.mec.gov.br/seb/arquivos/pdf/linguagens02.pdf.>. Acesso em:4 nov. 2017.

BRASIL. Ministério da Educação, Secretaria de Educação Básica-SEB. PNLD 2017: história - Ensino fundamental anos finais/ Ministério da Educação - Secretaria de Educação Básica SEB - Fundo Nacional de Desenvolvimento da Educação. Brasília, DF, 2016.

BRASIL. Ministério da Educação, Secretaria de Educação Básica - SEB,.PNLD 2016: história - Ensino fundamental anos iniciais. Brasília, DF, 2016.

BUONO CALAINHO, Daniela; FERREIRA, Jorge; VAINFAS, Ronaldo; CASTRO FARIA, Sheila de. História.doc. São Paulo: Saraiva Educação, 2015. 
CAMARGO, Eliane; Villar, Diego et. al. (Orgs.) HuniKuinHiwepaunibuki: a história dos caxinauás por eles mesmos / La historia de loscashinahuas por ellosmismos. São Paulo: SESC São Paulo, 2013.

CAMPOS, Flávio de; DOLHNIKOFF, Miriam; CLARO, Regina. História nos dias de hoje. São Paulo: Leya, 2015.

CERQUEIRA, Célia; PONTES, Maria Aparecida; SANTIAGO, Pedro. Integralis: História. São Paulo: IBEP, 2015.

COTRIM, Gilberto; RODRIGUES, Jaime. Historiar. São Paulo: Saraiva Educação, 2015.

CUNHA, Manoela Carneiro (Org). História dos índios no Brasil. São Paulo: Cia. Das Letras, 1992.

CUNHA, Manuela Carneiro. O efeito Lévi-Strauss: Anotações para uma conferência na USP. Tempo Brasileiro, v. 175, p. 120, 2009.

DIAS Adriana; GRINBERG, Keila; PELLEGRINI, Marco. Vontade de saber: História. São Paulo: FTD, 2015.

DOMINGUES, Ângela. Quando os índios eram vassalos: colonização e relações de poder no Norte do Brasil na segunda metade do séc. XVIII. Lisboa: CNCDP, 2000.

ESPÍNDOLA, Haruf S. Sertão do Rio Doce. Bauru: EDUSC, 2005.

FARAGE, Nádia. As muralhas dos sertões: os povos indígenas no Rio Branco e a colonização. Rio de Janeiro: Paz e Terra, 1991.

FAUSTO, Carlos. Inimigos fiéis: história, guerra e xamanismo na Amazônia. São Paulo: EdUSP, 2002.

FERNANDES, Florestan. A função social da guerra na sociedade tupinambá. São Paulo: Globo, 2006.

FREIRE, Paulo. Pedagogia da autonomia: saberes necessários à prática educativa. São Paulo: Paz e Terra, 1997.

FREIRE, Paulo. Educação como Prática da Liberdade. Rio de Janeiro: Paz e Terra, 1971.

GIROUX, Henry. Escola Crítica e Política Cultural. São Paulo: Cortez, 1992.

GOMES, Nilma Lino. Educação e relações raciais: discutindo algumas estratégias de atuação. In: MUNANGA, Kabengele (org.) Superando o racismo na escola. Brasília: MEC, 1999.

GOMES, Nilma Lino. Relações Étnico-Raciais, Educação e Descolonização dos Currículos. In: Currículo sem Fronteiras, v.12, n.1, pp. 98-109, Jan/Abr 2012.

GRANDE, Sandy. Red Pedagogy: Native American social and political thought. Lanham: Rowman\&Littlefield, 2004.

KUENZER, A. Z. A formação de professores para o ensino médio: velhos problemas, novos desafios. In: Educação e Sociedade, Campinas, v. 32, n. 116, p. 667-688, jul.-set. 2011.

LAS CASAS, Bartolomé de. Brevísimarelación de ladestruición de lasIndias. Madrid: Ediciones Cátedra, 1982.

LIMA, Amanda Machado Alves de. O livro indígena e suas múltiplas grafias. 2012. 155f. Dissertação - Faculdade de Letras da Universidade Federal de Minas Gerais, Belo Horizonte.

MANN, Charles. 1491: new revelations of the Americas before Columbus. New York: Vintage Books, 2005.

MATTOS, Izabel Missagiade. Civilização e Revolta: os Botocudos e a catequese na Província de Minas. Bauru, SP: EDUSC, 2004. 
MAXACALI, Índios. Peñahã: livro de Pradinho e Água Boa. Belo Horizonte: FALE/UFMG, 2005.

MAXAKALI, Índios. Hitupmãax: curar. Belo Horizonte: Faculdade de Letras da UFMG; Cipó Voador, 2008.

MAXAKALI, Toninho [et al.]; Tugny, Rosângela (Org.). Xunimyõgkutex xi hemexyõgkutex. Belo Horizonte: FALE/UFMG, 2013.

METCALF, Alida. Go-betweens and the colonization of Brazil, 1500-1600. Austin: University of Texas Press, 2005.

METCALF, Alida; DUFFY, Eve. The return of Hans Staden: a go-between in the Atlantic World. Baltimore: John Hopkins University Press, 2012.

MOCELLIN, Renato; CAMARGO, Rosiane de. Projeto Apoema: História. São Paulo: Editora do Brasil,2015.

MONTEIRO, John Manuel. Negros da terra: índios e bandeirantes nas origens de São Paulo. São Paulo: Cia. das Letras, 1994.

PEREIRA (ISKUHU), Edílson [etal.]. Shawãshãdipahu: histórias do povo Shawãdawa (Arara). Rio de Janeiro/Acre: Museu do Índio/CPI-AC, 2009.

POMPA, Cristina. Religião como Tradução: missionários, Tupi e Tapuia no Brasil Colonial. Bauru: Edusc, 2003.

PROFESSORES Indígenas de Rondônia e noroeste do Mato Grosso. Do açaí cada fruto uma história: narrativas dos povos indígenas de Rondônia e noroeste do Mato Grosso. Belo Horizonte: FALE/UFMG; CipóVoador, 2009.

RICHTER, Daniel K. Facing East from Indian country: a native history of early America. Cambridge: Harvard University Press, 2001.

RÜSEN, Jörn. O livro didático ideal. In: SCHMIDT, Maria Auxiliadora; BARCA, Isabel; MARTINS, Estevão de Rezende (Org.). Jörn Rüsen e o ensino de história. Curitiba: Ed. UFPR, 2011, pág. 109-128.

SANTOS, Boaventura de Sousa; MENESES, M,ária Paula. Epistemologias do Sul. São Paulo: Cortez, 2010.

VAINFAS, Ronaldo. A heresia dos índios: catolicismo e rebeldia no Brasil Colonial. São Paulo: Companhia das Letras, 1995.

VARNHAGEN, Francisco Adolpho de. História Geral do Brasil. Tomo 1. 5a ed. São Paulo: Melhoramentos, 1953.

VAZ, Maria Luisa; PANAZZO, Silvia. Jornadas. Hist: História. São Paulo: Saraiva Educação, 2015.

VICENTINO, Cláudio; VICENTINO, José Bruno. Projeto Mosaico: História. São Paulo: Scipione, 2015.

WITTMANN, Luísa Tombini. O vapor e o botoque: imigrantes alemães e índios Xokleng no Vale do Itajaí/SC (1850-1926). Florianópolis: Letras Contemporâneas, 2007.

XAKRIABÁ, Índios; ALMEIDA, Maria Inês (Org.). Encontros traduções. Belo Horizonte: FALE/UFMG, 2009. 
Da história dos índios às histórias indígenas: descolonizando o ensino de história

\section{Notas}

${ }^{1}$ Este artigo foi elaborado a partir de dados coletados pela pesquisa (...), financiada pela Fundep.

${ }^{2}$ Lei 9.394 de 20/12/1996. http://portal.mec.gov.br/seesp/arquivos/pdf/lei9394_ldbn1.pdf. Acesso em 18 de julho de 2017.

${ }^{3}$ Site: https://pib.socioambiental.org/pt/c/no-brasil-atual/quem-sao/povos-indigenas. Acesso em $16 \mathrm{de}$ julho de 2017.

${ }^{4} \mathrm{O}$ Acervo Indígena da UFMG (ACIND) reúne cerca de 230 livros de autoria indígena publicados no Brasil desde 1995.

${ }^{5}$ Ratificada pelo Congresso Nacional, através do Decreto Legislativo no 143, de 20.7.2002, publicado no Diário Oficial da União - D.O.U., em 21.6.2002 e entrada em vigor em 25.7.2003. Promulgada pelo Poder Executivo através do Decreto 5.051, de 19.4.2004, D.O.U. de 20.4.2004.

${ }^{6}$ Site: http://www.planalto.gov.br/ccivil_03/_ato2007-2010/2008/lei/111645.htm. Acesso em 18 de julho de 2017.

${ }^{7}$ Jörn Rüsen é um historiador e filósofo alemão cujos trabalhos abrangem os campos da teoria e metodologia da história, história da historiografia e didática da história. No Brasil, tornou-se mais conhecido pelos trabalhos no campo da Didática da História.

${ }^{8}$ Entre os pesquisadores que trabalham neste sentido, esta pesquisa tem como referência as contribuições da própria Manuela Carneiro da Cunha (organizadora de História dos índios no Brasil, 1992; autora de Cultura com aspas e outros ensaios, 2009), John Manuel Monteiro (Negros da terra, 1996), Carlos Fausto (Inimigos fiéis: história, guerra e xamanismo na Amazônia, 2001), André Prous (O Brasil antes dos brasileiros, 2006) Eduardo Neves (Arqueologia da Amazônia, 2006) e Eduardo Viveiros de Castro (A inconstância da alma selvagem, 2002). São autores não-indígenas que têm renovado o conhecimento sobre a história indígena.

* Doutora em Educação pela Universidade Federal de Minas Gerais, Belo Horizonte, Minas Gerais, Brasil.

** Professor adjunto IV do Departamento de Métodos e Técnicas de Ensino da Faculdade de Educação da Universidade Federal de Minas Gerais, Belo Horizonte, Minas Gerais, Brasil. 
Nayara Silva de Carie - Pablo Luiz de Oliveira Lima

\section{Correspondência}

Pablo Luiz de Oliveira Lima - Universidade Federal de Minas Gerais, Faculdade de Educação. Avenida Antônio Carlos, 6627. Pampulha. CEP: 31270901. Belo Horizonte, Minas Gerais, Brasil.

E-mail: carienayara78@gmail.com - plolima@yahoo.com

Recebido em 27 de junho de 2018

Aprovado em 07 de agosto de 2018

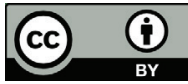

This work is licensed under a Creative Commons Attribution 4.0 International (CC BY 4.0). 